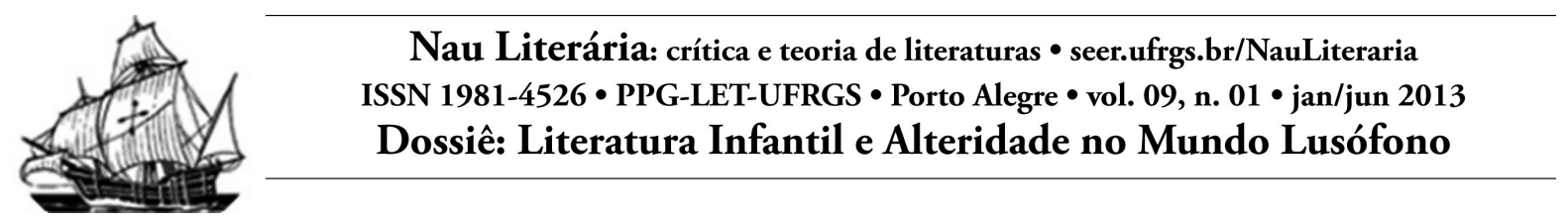

\title{
Infância, violência e "guineidades"
}

\author{
Erica Cristina Bispo
}

Resumo: A colonização e o pós-colonialismo geraram uma nova concepção de infância, que é encurtada e/ou apagada por razões sócio-políticas. A violência da colonização, a luta pela independência e a distopia da pós-colonialidade colaboraram para o ingresso de crianças no mercado do trabalho, legalizado ou não. Sob esse cenário, a literatura contemporânea bissau-guineense delineia a imagem da criança em diferentes aspectos. Em Odete Semedo, vemos a influência das tradições no cotidiano dos guineenses, suas obras em prosa trazem, por exemplo, o drama de crianças que precisam se adequar às necessidades da família para suprir a demanda dos Irans. Em Abdulai Sila, as imagens da criança e da adolescência denunciam os males coloniais. Em Tony Tcheka, fica evidente o drama da criança que precisa trabalhar para sobreviver. É nossa pretensão verificar, a partir das especificidades da Guiné-Bissau - religiões predominantes, problemas políticos e educacionais -, como a literatura de Odete Semedo, Abdulai Sila e Tony Tcheka refletem o real na arte, no que diz respeito à temática e à problemática da infância.

Palavras-chave: infância; Guiné-Bissau; Abdulai Sila; Odete Semedo; Tony Tcheka.

\begin{abstract}
The colonization and the post-colonialism generated a new childhood's conception, that is shortened and/or oblitered by social-political reasons. The colonization's violence, the struggle for the independence and the dystopia of post-colonialism collaborated to the access of children to the labour 's market, whether legalized or not. In this scenario, contemporary Guinea-Bissau's literature outlines the child's image in different aspects.. In Odete Semedo, we see the influence of traditions on guinean's everyday, her work on prose bring, for example, the drama of children that have to adequate themselves to their families needs of supplying Irans's demands.. In Abdulai Sila, the images of the child and the adolescence report the colonial's misdoings. In Tony Tcheka, rests evident the drama of the child that needs to work to survive. It's our intention to verify, from Guinea-Bissau's specifities prevailing religions, political and educational issues - how Odete Semedo's, Abdulai Sila's and Tony Tcheka's literature reflect the reality in art, regarding the theme and the problematization of childhood.
\end{abstract}

Keywords: childhood; Guinea-Bissau; Abdulai Sila, Odete Semedo; Tony Tcheka.

Guiné

és tu

criança sem tempo de ser menino 
As palavras do poeta guineense Tony Tcheka no poema "Canto à Guiné" metaforizam a situação da Guiné-Bissau e também da infância no país. Com 39 anos de independência de Portugal, a Guiné não tem tempo de errar como menino, mas precisa agir como adulto e lidar com as intempéries dos tempos pós e neocoloniais. Guerras civis, fome, falta de infraestrutura básica, por exemplo, são problemas que distorcem o conceito de infância em solo africano e, de modo especial, bissau-guineense. Nas palavras da professora doutora Moema Augel, "a literatura é sem dúvida o espelho da sociedade em que se desenvolve e é uma das suas manifestações mais vivas" (AUGEL, 1998, p. 19). Sendo assim, a literatura, como manifestação cultural inserida num determinado momento da história, opera a fim de apontar e denunciar que, na Guiné-Bissau, a criança não tem tempo de ser menino.

Cada escritor, seja em verso ou em prosa, cumpre seu papel ao indicar artisticamente por que isso ocorre. Para este trabalho, utilizaremos três representantes da elite cultural do país: Abdulai Sila, Odete Semedo e Tony Tcheka.

Segundo o historiador Joseph Ki-Zerbo, "não havia etnias fechadas no sistema africano pré-colonial, sempre houve entre as etnias uma mistura fantástica, que é demostrada pelo mapa atual dos povos africanos" (KI-ZERBO, 206, p. 154), tal mescla se revela de modo bastante emblemático no que se refere às crenças autóctones. Há na África negra um sincretismo que em muito se difere do que ocorre no Brasil. É comum, para muitos africanos, agregar crenças e tradições, de acordo com a herança familiar. Num toka-tchur ${ }^{2}$, por exemplo, realiza-se a cerimônia típica da etnia da mãe do defunto, do pai, do marido e, no caso de o morto ter aderido a uma religião como islamismo ou

\footnotetext{
${ }^{1}$ TCHEKA, Tony. Guiné: sabura que dói. São Tomé: UNEAS, 2008.

${ }^{2}$ Cerimônia fúnebre.
} 
cristianismo, também há o culto correspondente. Na versão ficcionalizada da cerimônia, Odete Semedo declara: "muitos mesmo querendo não podem fugir a esses rituais" (SEMEDO, 2000, p. 67). A presença das crenças tradicionais compõe a rotina do povo. E o conto "Sonéá", de Odete Semedo, mostra como essa mescla interfere na vida da criança.

Numa narrativa que começa em função de um ritual de toka-tchur, o leitor conhece Sonéá, uma mulher do século XXI, inserida no contexto da contemporaneidade guineense, mas que, ainda assim, precisa preservar a tradição.

Durante a infância, Sonéá precisou deixar a cidade e seguir para a tabanca ${ }^{3}$ de seus familiares a fim de cumprir obrigações exigidas pelos irans ${ }^{4}$ : tratava-se do casamento da menina com o velho tio Kilin. "Era um casamento para manter a tradição e acontecia sempre que os defuntos da linhagem materna - djorson di bariga ${ }^{5}$ - assim o exigissem" (SEMEDO, 2000, p. 93). O pedido dos antepassados abalara a todos, mas não houve saída e realizou-se a cerimônia. A despeito da pouca idade, mesmo com a dor sentida pela família e a indignação demonstrada por todos os participantes do evento, Sonéá, como membro daquela sociedade, precisou contrair casamento. Ignorou-se a infância e considerou-se, nesse contexto, o dever.

O evento, apesar de áspero, quando lido num contexto ocidental, é amenizado pelo tom de saudade da protagonista. As lembranças de Sonéá, já adulta, que rememoram o ocorrido, descrevem com imensa doçura a relação com tio Kilin, cujo trato era bastante carinhoso.

A relação sexual que se pressupõe com um casamento não é relatada, nem tampouco mencionada. Os encontros entre Sonéá e Kilin, no conto, se restringem a longas conversas sobre a natureza, o mundo, Deus e a tradição.

\footnotetext{
${ }^{3}$ Aldeia.

${ }^{4}$ Nome dado a divindades tradicionais, que representam famílias e antepassados.

${ }^{5}$ Linhagem materna.
} 
Dessa forma, Odete Semedo, consegue inserir a tradição na literatura não apenas recriando as histórias da oralidade, mas também revelando como a tradição permanece viva no cotidiano do guineense.

Além disso, Odete revela como a criança é inserida no contexto tradicional, a criança faz parte do clã, sendo responsável pela manutenção do núcleo familiar, seja pelo casamento tradicional, pelo toka-tchur ou por qualquer outro rito.

O pesquisador guineense Carlos Cardoso explica que a compreensão das questões africanas passa pela herança colonial, as práticas de exploração, repressão e paternalismo etnocêntrico (cf. CARDOSO, 1997 apud AUGEL, 1998, p. 427-428), sendo assim, a visita ao período colonial também nos revela outro aspecto da infância guineense: a troca dos brinquedos pelo trabalho. A partir de um olhar pós-colonial, Abdulai Sila pensa a adolescência durante o período colonial. Em $A$ última tragédia, o ficcionista apresenta a personagem Ndani, que, aos 13 anos, sai de sua tabanca, em Biombo, em direção a Bissau para ser criada. Na década de 1950, há poucas opções para uma adolescente nativa como Ndani. Vivendo na tabanca, ela estaria fadada a não ter educação formal; seguindo para a cidade, as oportunidades não seriam muito mais amplas, entretanto, sob o olhar de Ndani, Bissau é a forma de experimentar do "diferente mundo dos brancos". Como pagamento por essa experiência, Ndani teria apenas que "lavar roupa, limpar o chão e [...] preparar alguns pratos de peixe e carne da maneira como os brancos gostam" (SILA, 2006, p. 25).

$\mathrm{O}$ romance denuncia a diferença entre a adolescência dos negros e dos brancos no período colonial. Numa das primeiras cenas, Ndani está a pedir trabalho em frente à casa de um casal que a ignora, e o narrador questiona "se tivessem encontrado uma menina branca com fome e sede, tê-la-iam também abandonado?" (SILA, 2006, p. 29). As crianças negras tinham que brigar por comida diariamente, além de ter que começar a trabalhar muito cedo, enquanto 
os filhos dos brancos iam à escola todos os dias. Ou seja, a colonização criou duas classes muito distintas de pessoas: o colonizador e o colonizado, onde este seria inferior àquele, e essa condição estaria marcada desde a infância. Não há o questionamento do status quo estabelecido pela colonização, e isso colabora com a manutenção da situação.

Além de negar a educação formal, o colonizador também se mostra proprietário do colonizado. A relação de Ndani com os patrões retrata isso. Dona Linda e Senhor Leitão agridem a adolescente com palmatória e puxões de orelha. A violência física da qual Ndani é vítima é metonímia da agressão colonial vivida pelo país. O ápice desse movimento é a violência sexual. Ndani é violentada aos 15 anos pelo patrão que entende que o corpo da moça é sua propriedade. Essa relação metaforiza o pacto colonial entre Portugal e GuinéBissau, no qual aquele se vale desta para extrair as benesses que lhe interessam.

A violência contra a infância guineense é um aspecto literário presente ao se olhar o passado e que permanece no relato da contemporaneidade. Mesmo após a independência, a infância não deixou de conter fome ou falta de escola. $\mathrm{O}$ poeta Tony Tcheka, em seus livros Noites de insónia na terra adormecida (1996) e Guiné: sabura que dói (2008), traz poemas com temáticas diferenciadas, mas sempre explicitando as questões do país, dentre elas a infância. Desse poeta, queremos destacar o texto "Chamo-me menino", que integra a parte "Canto menino", do primeiro livro do autor.

\section{Chamo-me menino}

Sou criança pobre de uma rua sem nome de um bairro escuro de covas fundas em garganta fatalmente magra carente de pão e sem muita ambição Sou filho da miséria escancarada 
enteado da vida

entreaberta

Vivo na periferia

passo no tempo

com trejeitos de homem

Chamo-me Menino!

Dou passes desde os cinco

tenho doze chuvas

uma cara operária

sobre um corpo fininho

de cinco anos

Sofro de raquitismo

por comer com os olhos

enquanto na garganta

destilam bolas de saliva

Meu peito nicotizado

é mortalha e tantã

arde e inflama

como a chama!

(TCHEKA, 1996, p. 117-118)

Inicialmente, podemos reparar, neste poema, a identidade do eu-lírico, que declara chamar-se "Menino" (com letra maiúscula). A igualação do substantivo próprio ao substantivo comum nos revela a não identidade e a identificação do sujeito. O eu-lírico é singular, por ser apenas um menino; mas também é metonímia de um coletivo de crianças que vivenciam a mesma situação que ele.

A falta de identificação específica não se limita ao nome, mas estende-se, também, ao local de origem: "de uma rua sem nome". Ao mesmo tempo em que essa informação desenraiza o eu-lírico de qualquer lugar, também o radica em todos os lugares. Assim, enfatiza-se a identificação do eu-lírico com várias crianças do país, de diversas regiões do país.

Essa criança que é múltipla, porque tem todos os nomes e vem de todos os lugares, apresenta, também, dificuldades comuns a outras tantas: o Menino é "carente de pão", "filho da miséria" e sofre de raquitismo. Tony Tcheka denuncia aqui a fome, provavelmente o maior problema do continente africano. 
Tanto o governo colonial quanto o nacional não conseguiram ainda oferecer à população os meios básicos para a subsistência. No caso do Menino (com letra maiúscula), seu problema é maior, pois, como não tem pais, suas chances de sobrevivência são menores, bem como sua expectativa de vida. Aliás, o Menino se identifica como sendo "enteado da vida", que é uma forma eufêmica para afirmar que a vida é sua madrasta. Sua mãe é a miséria.

Para driblar a fome, o Menino dá "passes desde os cinco", ou seja, ele "se vira". Não fica evidente como o Menino trabalha, mas ele faz isso desde a tenra idade. Fica explícito, por outro lado, que o conceito de infância como conhecemos - brincar, aprender e divertir-se - não compõe a rotina do eu-lírico. Em vez disso, o Menino luta para continuar vivo mais um dia.

Ao passar por três escritores guineenses, concluímos que as "guineidades" ora afastam, ora aproximam a criança bissau-guineense das demais crianças africanas. Notamos que, em toda a África, como também ocorre no Brasil, há crianças que deixam a infância porque precisam trabalhar. Contudo, na GuinéBissau, talvez a consciência da elite intelectual seja mais trágica do que em outros lugares, pois, ao olhar para trás, essa elite se dá conta de que a luta empreendida e o discurso propalado não se tonaram práticos, a igualdade pregada não se tornou real, nem tampouco a colonização deixou de existir. Mesmo sem guerras civis declaradas no território guineense, apesar da tensão constante $^{6}$, a Guiné não tem "tempo de ser menino", nem o menino pode ser criança.

\section{Referências}

AUGEL, Moema Parente. A nova literatura da Guiné-Bissau. Bissau: INEP, 1998.

\footnotetext{
${ }^{6}$ Há na Guiné-Bissau a sensação constante de uma guerra civil iminente. Nos últimos cinco anos, houve assassinatos de figuras proeminentes no cenário político. Há hodiernamente um constante estado de sítio.
} 
O desafio do escombro: nação, identidades e pós-colonialismo na literatura da GuinéBissau. Rio de Janeiro: Garamond, 2007.

BISPO, Erica Cristina. Gestos e vozes de papel: Odete Semedo e a reinvenção de passadas e estórias da tradição oral guineense. 2005. Dissertação (Mestrado em Letras Vernáculas) - Faculdade de Letras, Universidade Federal do Rio de Janeiro, Rio de Janeiro, 2005.

Resenha de A última tragédia. Disponível em $<$ http://www.africaeafricanidades.com.br/documentos/A ultima tragedia.pdf $>$. Acesso em $13 / 10 / 12$, às $16 \mathrm{~h}$.

CASTRO, Armando. O sistema colonial português em África (meados do século XX). Lisboa: Caminho, 1980.

KI-ZERBO, Joseph. Para quando África? Entrevista com René Holenstein. Tradução de Carlos Aboim de Brito. Rio de Janeiro: Pallas, 2006.

LOPES, Carlos (org.). Desafios contemporâneos da África: o legado de Amílcar Cabral. São Paulo: Unesp, 2012.

SEMEDO, Odete Costa. Sonéá: histórias e passadas que ouvi contar I. Bissau: INEP, 2000.

SILA, Abdulai. Mistida (Trilogia). Praia: Centro Cultural Português, 2002. . A última tragédia. Rio de Janeiro: Pallas, 2006.

TCHEKA, Tony. Noites de insônia na terra adormecida. Bissau: INEP, 1996. . Guiné: sabura que dói. São Tomé: UNEAS, 2008. 